University of Nebraska - Lincoln

DigitalCommons@University of Nebraska - Lincoln

$6-2020$

Documentando y conservando las colecciones plumarias del Museo Etnográfico Juan B. Ambrosetti; Facultad de Filosofía y Letras, Universidad de Buenos Aires

Silvana Di Lorenzo

Silvia Manuale

Follow this and additional works at: https://digitalcommons.unl.edu/pctviii

Part of the Art and Materials Conservation Commons, Fiber, Textile, and Weaving Arts Commons, Indigenous Studies Commons, Latin American Languages and Societies Commons, Museum Studies Commons, and the Other History of Art, Architecture, and Archaeology Commons

This Article is brought to you for free and open access by the Centre for Textile Research at DigitalCommons@University of Nebraska - Lincoln. It has been accepted for inclusion in PreColumbian Textile Conference VIII / Jornadas de Textiles PreColombinos VIII (2019) by an authorized administrator of DigitalCommons@University of Nebraska - Lincoln. 


\title{
Documentando y conservando las colecciones plumarias del Museo Etnográfico Juan B. Ambrosetti; Facultad de Filosofía y Letras, Universidad de Buenos Aires
}

\author{
Silvana Di Lorenzo* \& Silvia Manuale ${ }^{\dagger}$ \\ * Museo Etnográfico Juan B. Ambrosetti, FFyL, UBA (sildilor@hotmail.com) \\ † Instituto de las Culturas (IDECU - CONICET)
}

\begin{abstract}
Resumen
Los pueblos originarios de la región sur de América hicieron y hacen uso de las plumas de aves locales para la elaboración de indumentaria y artefactos rituales, a través de complejas manufacturas que combinan conocimiento de técnicas textil y plumaria. En este trabajo presentamos la problemática de conservación y documentación de las colecciones plumarias del Gran Chaco, actualmente conservadas en el Museo Etnográfico Juan Bautista Ambrosetti, señalando la importancia del registro gráfico y fotográfico, herramientas metodológicas fundamentales para la documentación y la conservación de colecciones etnográficas.
\end{abstract}

Palabras claves: Conservación textil, documentación textil, Gran Chaco, Museo Ambrosetti, artefactos plumarios.

\begin{abstract}
The indigenous peoples of the South American region made and make use of the feathers of local birds for the manufacture of clothing and ritual artefacts, through complex manufactures that combine knowledge of textile and featherwork techniques. In this paper we present the problem of conservation and documentation of the feather collections of the Gran Chaco, at this moment preserved in the Juan Bautista Ambrosetti Ethnographic Museum, pointing out the importance of the graphic and photographic record, fundamental methodological tools for the documentation and conservation of ethnographic collections.
\end{abstract}

Keywords: Textile conservation, textile documentation, Gran Chaco, Ambrosetti Museum, feather ornament.

\section{Résumé}

Les peuples originaires de la région sud-américaine ont fait et continuent de faire usage des plumes d'oiseaux locaux dans l'élaboration des tenues et des artefacts rituels, à travers des manufactures complexes qui combinent la connaissance des techniques textiles et celles associées aux plumes. Dans cet article nous présentons le problème de la conservation et de la documentation des collections d'objets en plumes du Gran Chaco, actuellement conservés au Musée Ethnographique Juan Bautista Ambrosetti, en soulignant l'importance des registres graphiques et photographiques, outils méthodologiques fondamentaux pour la documentation et la conservation des collections ethnographiques.

Mots-clés: Conservation textile, documentation textile, Gran Chaco, Musée Ambrosetti, artefacts en plumes.

DOI: $10.32873 /$ unl.dc.zea.1219

Published in PreColumbian Textile Conference VIII / Jornadas de Textiles PreColombinos VIII, ed. Lena Bjerregaard and Ann Peters

(Lincoln, NE: Zea Books, 2020). https://digitalcommons.unl.edu/zeabook/ 


\section{Introducción}

El Museo Etnográfico de la Universidad de Buenos Aires almacena y exhibe un amplio acervo de origen arqueológico y etnográfico procedente de varias partes del mundo. Desde los objetos locales, tales como los textiles arqueológicos de las sociedades del noroeste argentino, las miniaturas incas halladas en Catamarca, pasando por los tejidos andinos provenientes de Perú, hasta los objetos etnográficos, productos de los pueblos nativos de los cinco continentes; entre ellos, es destacable un conjunto de objetos etnográficos plumarios de la región que Argentina comparte principalmente con $\mathrm{Pa}$ raguay y Bolivia, denominada Gran Chaco.

El objetivo de este artículo es presentar la modalidad de trabajo para la preservación de las colecciones plumarias, haciendo referencia al proceso de documentación utilizado durante las prácticas de conservación y enmarcándolo en el concepto más amplio de la conservación preventiva. Se señala además, la metodología de investigación relacionada con la adquisición de información para documentar y realizar adecuados diagnósticos del estado de conservación de los objetos patrimoniales, teniendo en cuenta la materialidad, el contexto de uso pasado y reconociendo el uso actual por parte de las comunidades originarias.

Finalmente, se hace específica mención a las acciones de conservación preventiva para el manejo de las colecciones etnográficas cuyo componente principal es la pluma, un material de origen orgánico, altamente sensible a la degradación debido a múltiples factores.

\section{Documentar para conservar y conservar para documentar}

El trabajo de conservación en los museos o instituciones que resguardan objetos patrimoniales implica diferentes procedimientos a partir de un plan de preservación para el manejo de las colecciones. La documentación atraviesa todo el desarrollo de conservación del patrimonio, constituyéndose en procesos entrelazados con el fin de obtener un registro de todo lo que concierne a cada objeto, desde la materialidad, la técnica de manufactura, la forma, hasta la información o biografía del objeto, relacionada con los usos pasados y la historia del objeto dentro de la institución (Alvarado Pérez y Azócar Magüida 1994). De esta manera, es importante conocer y registrar la naturaleza o la composición química de cada objeto de la colección, analizar la forma de elaboración, los posibles rastros de uso y los diferentes tratamientos a los que fue sometido durante su estancia en la institución, para poder preservar el objeto en sí mismo y a la información contenida. Y esta tarea de documentación antecede a cualquier tipo de intervención, como así también todo el proceso de conservación y restauración debe ser documentado para que en el futuro otros profesionales puedan evaluar los cambios en el estado de conservación y discernir los agregados durante la restauración de los objetos.

\section{La fotografía y el dibujo como herramientas para la documentación en conservación:}

La manipulación del material plumario es uno de los factores principales en la producción de deterioros del componente proteico, teniendo en cuenta la alta fragilidad estructural de la pluma; por lo que se torna imprescindible la aplicación de una metodología singular que permita minimizar las alteraciones físicas y químicas.

La fotografía y el dibujo se sugieren como herramientas metodológicas adecuadas para la documentación y a la vez la preservación de las colecciones de origen orgánico.

El registro fotográfico es fundamental para la identificación de un objeto patrimonial en el inventario de una colección, y además es de suma importancia para documentar toda la información relacionada con el estado de conservación y los diferentes tratamientos de conservación y restauración. Por otro lado, es un recurso importante para evitar la excesiva manipulación, facilitando el acceso a los objetos para la consulta y la investigación (Roubillard Escudero 2008).

Aunque se ha planteado que la fotografía es un recurso más objetivo para el registro de un objeto que el dibujo (Icon News 2015), es importante señalar que existe una diferencia sustancial entre el dibujo científico y el artístico, lográndose mayor objetividad de representación del material a través de diferentes convenciones con el primer tipo de representación gráfica.

La fotografía es útil para obtener un registro acabado del objeto y también nos posibilita cierto detalle a través de sus lentes macro. Mediante la observación de estas imágenes es posible realizar los registros gráficos sin manipular directamente el objeto.

El dibujo no copia sólo la apariencia de un objeto sino que recrea una imagen artificial del mismo. Este es el resultado de la práctica de la observación sobre el objeto, seguida por la deconstrucción analítica mental y luego su reconstrucción sobre el papel en una manera que presenta más claramente los rasgos observados ${ }^{1}$ (Icon News 2015:11).

La constante observación del objeto real se va tornando abstracta en la mente del dibujante y esa abstracción a su vez se vuelve real; y esa realidad es la copia del objeto concreto. 


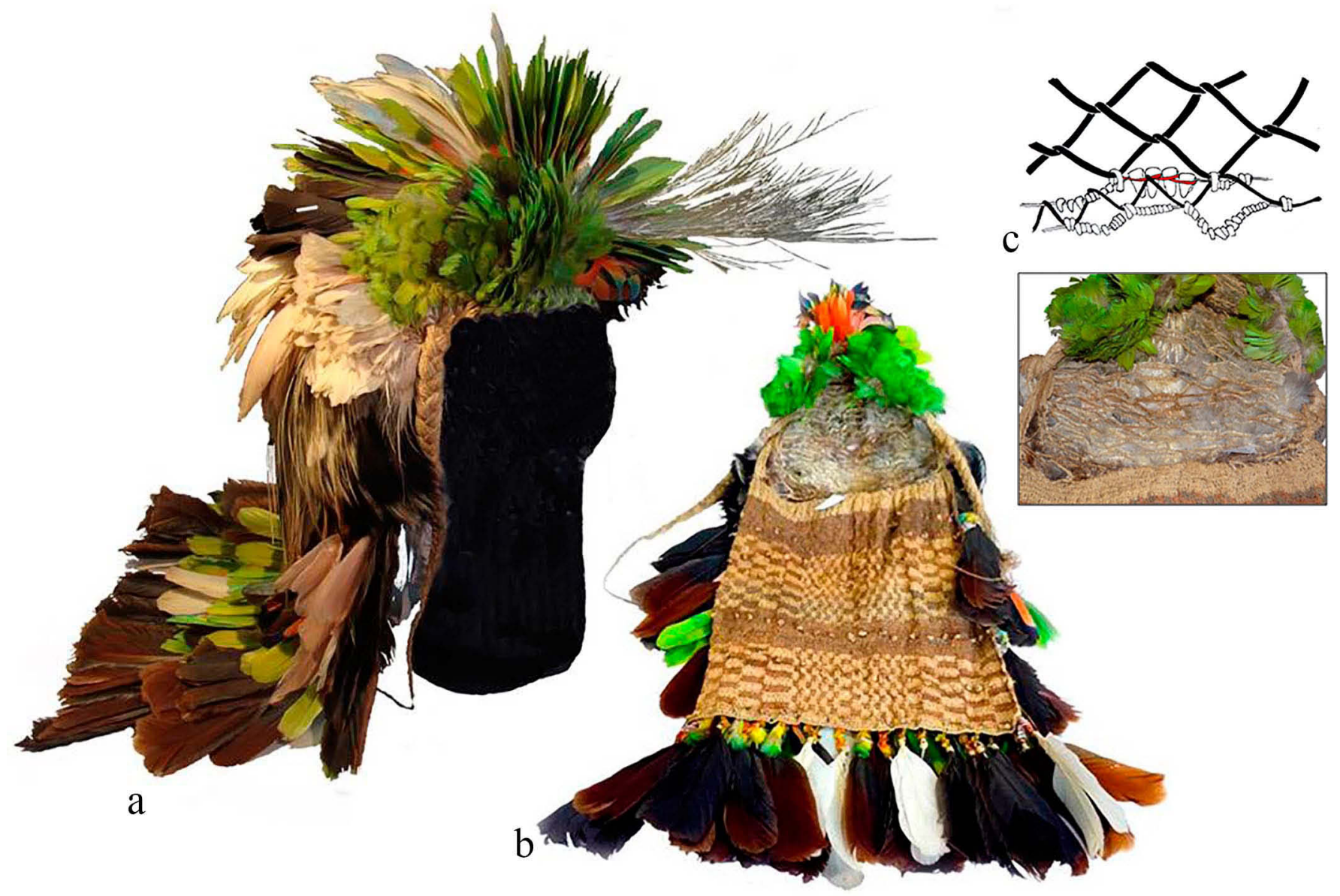

Figura 1. Tocado ishir $N^{\circ} 6265$ (ME, FFyL, UBA). a. Anverso; b. Reverso; c. Técnica plumaria: enlaces de hileras de plumas en el gorro y unión de gorro con cubrenuca (dibujo por Silvia Manuale).

Según la mirada y el conocimiento del dibujante, se pueden mostrar de forma clara, precisa y simple los detalles, las formas y los diseños de un objeto. Además, el dibujo es una herramienta útil para mostrar el proceso de manufactura de un objeto en una secuencia de tiempo (Icon News 2015). Por ejemplo, en el caso particular de un tocado ishir (Figura 1), la parte superior puede ser representada en sus diversos pasos de manufactura: la técnica de las hileras de plumas sobre cordel base, los enlaces y anudados de las hileras; en la parte media, la unión del gorro con el cubrenuca y en la parte inferior queda registrada el tejido de malla junto a la inserción de los fustes o manojos de plumas mediante nudos.

Largas explicaciones textuales pueden ser simplificadas a través de un simple dibujo que muestre "una secuencia de movimientos dentro de una imagen única" (Icon News

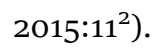

Así como el arqueólogo tiene su libreta de campo, el dibujante posee su libreta de apuntes donde plasma bocetos, notas diversas, medidas e ideas que ayudarán a la elaboración del trabajo final. Como afirma John Berger (2017: 61): "Dibujar no es sólo medir y disponer en el papel, sino que también es recibir". Podríamos agregar, recibir aquello que nos cuenta sobre lo que observamos, estableciéndose un diálogo permanente, una empatía tan profunda entre el dibujante y lo observado, que la mano parecería estar guiada por el alma del objeto, capturando con la mirada, intención y compromiso esa primera toma que llevará a la imagen definitiva.

A partir del análisis minucioso pueden surgir dudas, preguntas acerca de cómo habría sido confeccionado el objeto; aparecen las primeras hipótesis de las técnicas de manufactura, se aproximan las medidas o dimensiones y se las plasma en el papel. Se compara la bibliografía disponible y se buscan antecedentes ya publicados con las posibles 
denominaciones de las técnicas, la normativa, las convenciones y las clasificaciones ya establecidas, en el caso de que las hubiera; también se pueden realizar interconsultas con otros especialistas.

Es necesario volver a señalar que para la realización del trabajo detallado han sido muy útiles las fotografías obtenidas a través de lentes macro, las cuales nos acercan a detalles que difícilmente puedan ser vistos a simple vista.

\section{Las colecciones plumarias del Gran Chaco}

El Museo Etnográfico de la Universidad de Buenos Aires, cuyo creador y primer director fuera el naturalista y arqueólogo Juan B. Ambrosetti fue concebido como un lugar de formación, investigación y difusión a partir de la exhibición de colecciones procedentes de excavaciones arqueológicas y de aquella cultura material contemporáneamente producida por los pueblos originarios (Pegoraro y Elías 2010). De esta manera, parte del patrimonio etnográfico procedente del Gran Chaco fue recogido y donado durante las dos primeras décadas del siglo XX, y otra gran parte, provino de las expediciones del etnógrafo Enrique Palavecino, en la década de $1940^{3}$.

El denominado Gran Chaco americano es una extensa región que abarca la parte nordeste del territorio argentino, el sudeste de Bolivia, una muy pequeña porción de Brasil y un gran sector del Paraguay, cuyo límite oeste es el río homónimo (Figura 2). En este gran y diverso territorio, los pueblos originarios viven desde épocas ancestrales; producen y han producido una compleja cultura material, y algunos de sus objetos son actualmente conservados en este museo universitario.

Una variedad de textiles y partes de la indumentaria con plumas proceden de los pueblos pilagá, chorote, wichí, qom, ishir y ayoreo. Mantas, ponchos, fajas, bolsas, vinchas, tocados, brazaletes, diademas, tobilleras y cinturones constituyen el patrimonio etnográfico chaqueño preservado en la institución de Buenos Aires. La materialidad presente en el soporte textil de lana o de chaguar abarca la pluma, las mostacillas o cuentas de vidrio, las cuentas de valvas, los botones, y hasta aves disecadas (Figura 3).

Es de interés en este trabajo señalar aquellas partes de la vestimenta que utilizaron plumas, que en el caso de los pueblos del chaco paraguayo y boliviano, son de origen natural, aprovechando la gran variedad de aves locales de la región; y que en el lado argentino, algunas son utilizadas de forma natural y otras se tiñen para lograr colores difícilmente alcanzables en la naturaleza local.

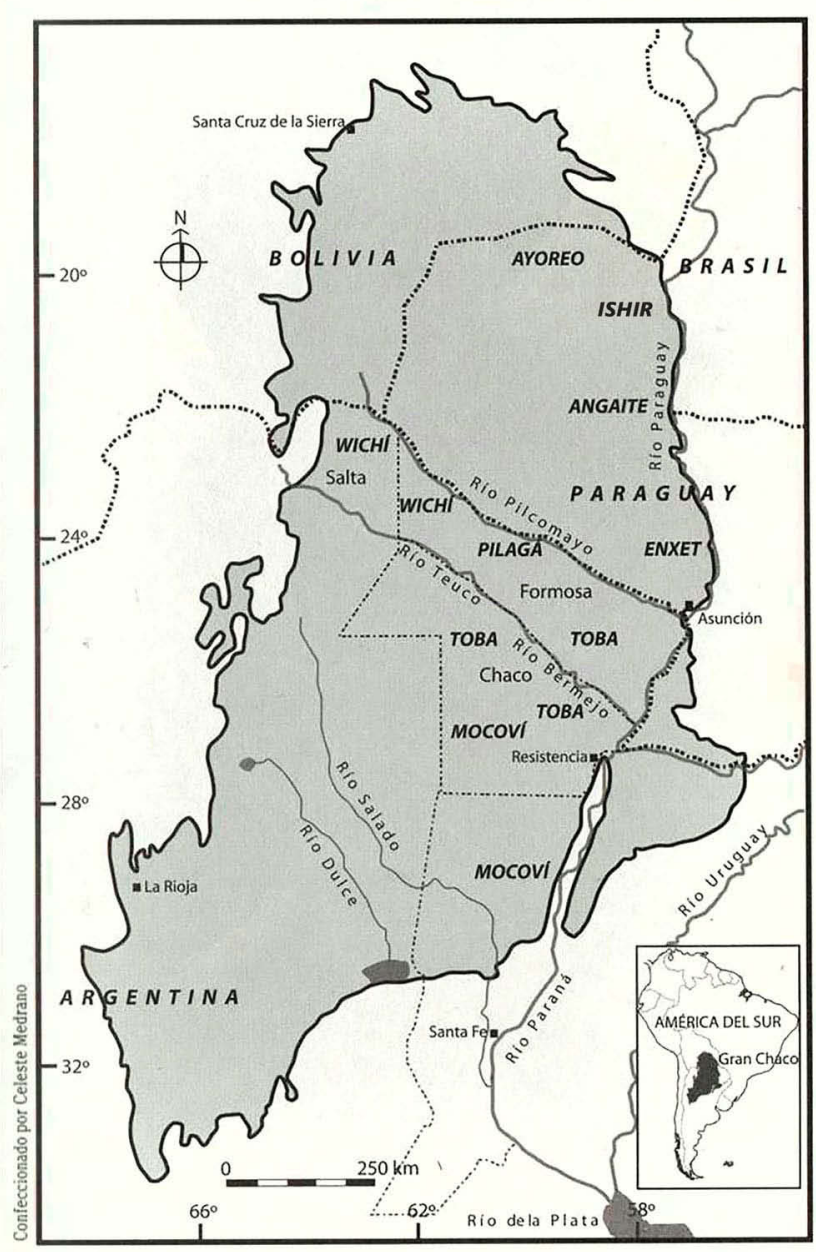

Figura 2. Mapa del Gran Chaco, realizado por Celeste Medrano (Tola F. 2016. Una historia más que humana. En: El teatro chaqueño de las crueldades. Memorias qom de la violencia y el poder, comp. F. Tola y V. Suárez. Ethnographica. Asociación civil Rumbo Sur - Consejo Nacional de Investigaciones Científicas y Tecnológicas -CONICET- Instituto de Investigaciones Geohistóricas - IIGHI: 34).

El estudio y análisis de la técnica plumaria en las diferentes áreas de la región nos permitió encontrar similitudes y diferencias entre las técnicas plumarias de los pueblos del chaco argentino y el paraguayo.

La técnica plumaria general y básica presente en vinchas, tocados, diademas y cinturones es la hilera de plumas sobre un cordel base con doblez del cálamo (Figura 4). De esta manera, se realiza la sujeción de las plumas enlazando a través de un cordel de fibra vegetal, el caraguatá o chaguar y doblando la parte inferior de la pluma, de modo tal que la unión quede firme a través del cordel. A partir de esa

3. Los objetos recolectados por Palavecino ingresaron originalmente al Museo de Ciencias Naturales B. Rivadavia, y por decreto del Ejecutivo, en 1947, se hizo el traspaso de todas las colecciones antropológicas al Museo Ambrosetti. 


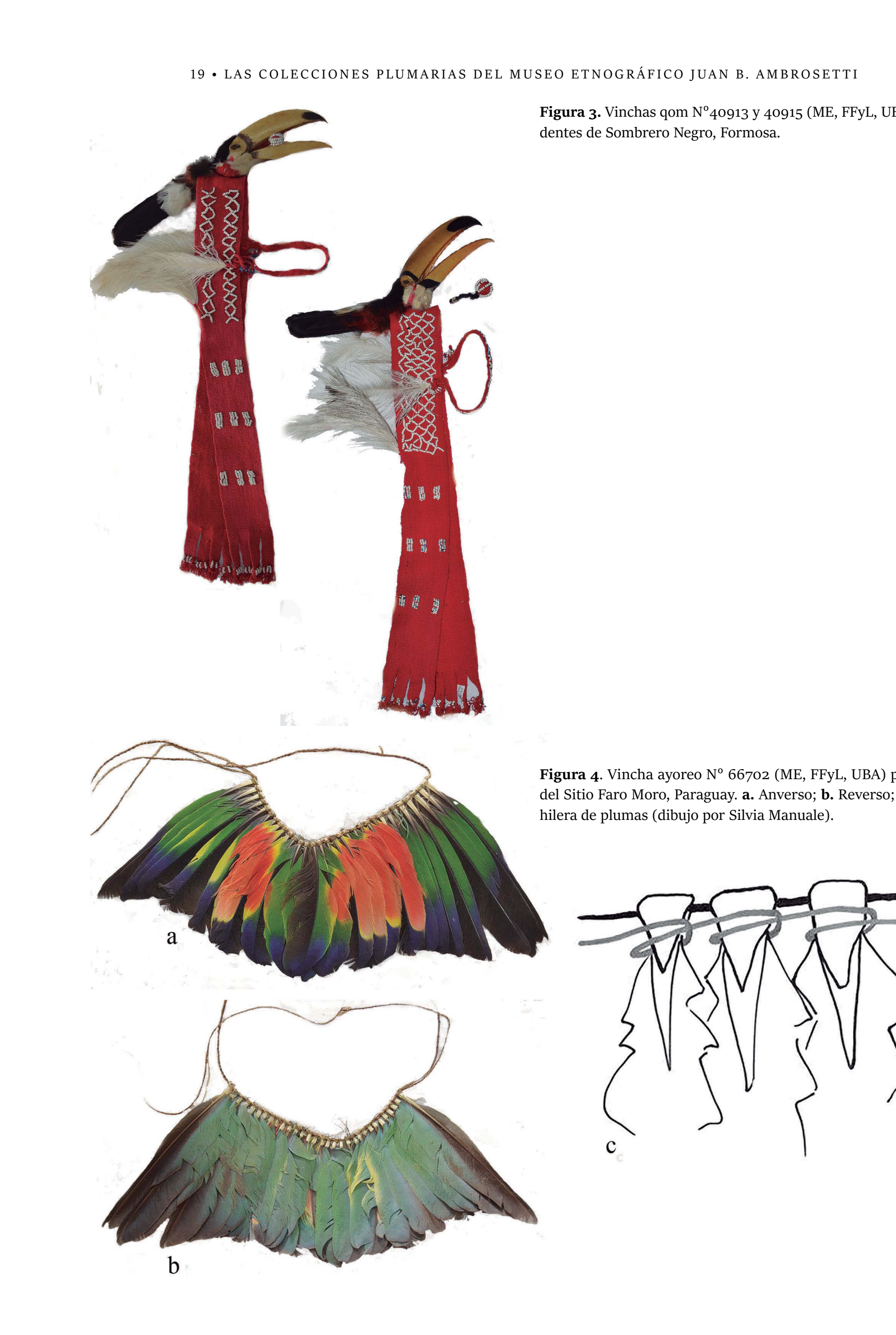



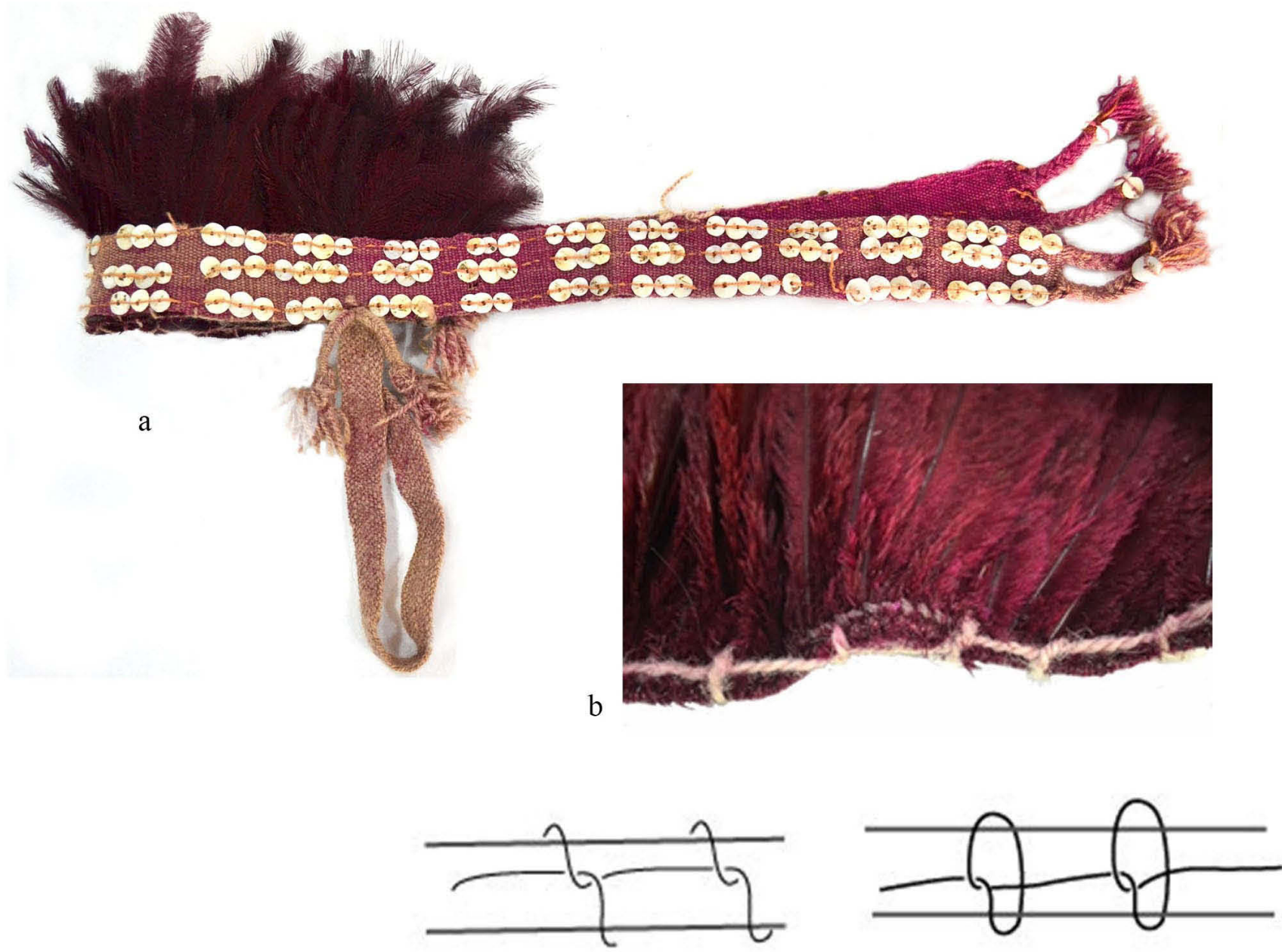

c

Figura 5. Vincha chorote $\mathrm{N}^{\circ} 44414$ (ME, FFyL, UBA), colección Debenedetti a. Vincha; b. Detalle de la sujeción de las plumas al textil; c. Técnica de sujeción, punto festón (dibujo por Silvia Manuale).

técnica de base se realizan otro tipo de amarres al tejido, como el festón en la vincha chorote (Figura 5) o los enlaces en los tocados ishir.

En el caso de la vincha pilagá tejida en lana teñida de roja, la sujeción de las plumas al textil se realiza mediante simples amarres con enlaces y nudo simple por medio de un cordel de caraguatá (Figura 6). Cuando la pluma es la protagonista principal, otro tipo de sujeciones más complejas pueden observarse en los cinturones y los adornos para miembros ishir. En uno de los cinturones, a partir de un cordel principal, se desprenden haces de plumas, que están sujetos mediante un wrapping o enrollado y nudo simple, mediante doblez del cálamo (Figura 7). En otro de los cinturones, con apliques de plumas coloridas del loro hablador, sobre cordel base, se enlazan pequeños fustes o manojos de plumas mediante enlaces con nudo simple (Figura 8). En las muñequeras, brazaletes o tobilleras, plumones verdes son sujetos en los intervalos de los nudos de una retícula (Ribeiro 1988) formada por los diferentes cordeles de chaguar (Figura 9).

Las técnicas textiles empleadas en las colecciones plumarias del Gran Chaco están representadas por la faz de urdimbre como es el caso de la vincha chorote realizada sobre un tejido de lana teñida (Figura 10); y la técnica de malla o enlaces interconectados figura en ocho (Seiler Baldinger 1994), como es el ejemplo de los tocados ishir, confeccionados sobre la fibra del caraguatá (Figura 11).

La indumentaria con plumas ha sido registrada en contextos de uso ceremonial y generalmente quienes la portan son líderes religiosos que en la literatura científica han sido denominados shamanes o chamanes, como entre los ishir del chaco paraguayo (Cordeu 1980; Escobar 2012). Existen registros publicados sobre el uso de vinchas con plumas con las características ya mencionadas así como otros tipos de 


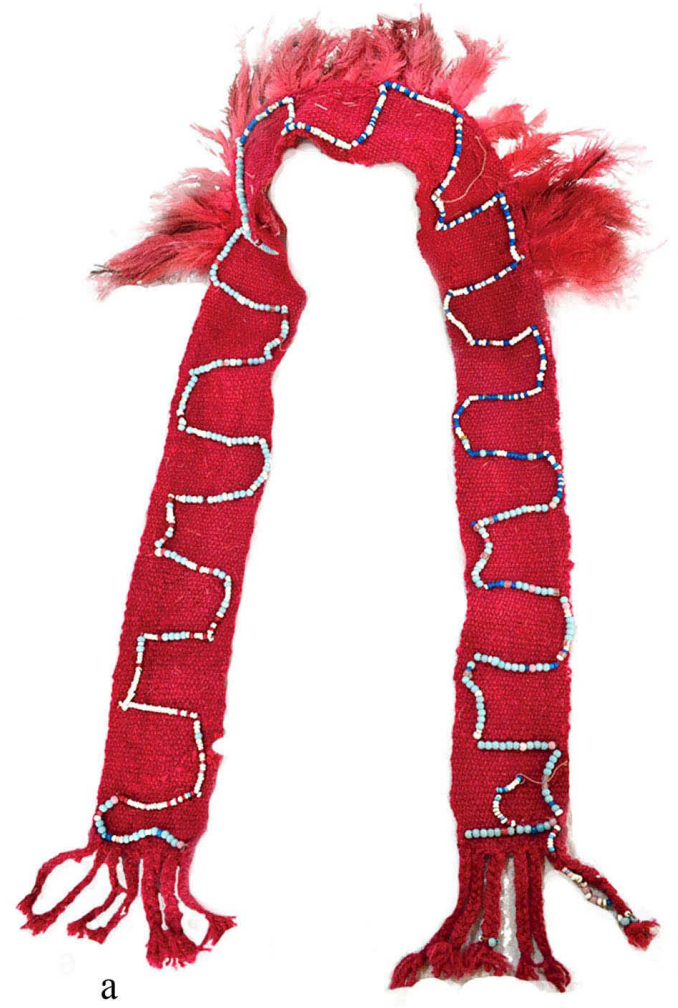

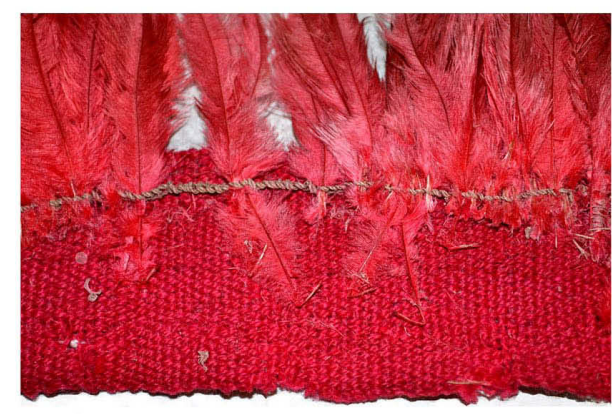

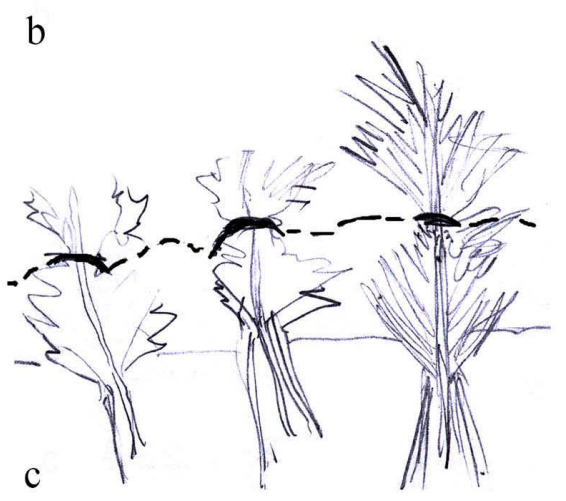

Figura 6. Vincha pilagá No 44904 (ME, FFyL, UBA), colección Palavecino. a. Vincha; b. Detalle de la sujeción de plumas al textil; c. Técnica de la sujeción de plumas al tejido (dibujo por Silvia Manuale).

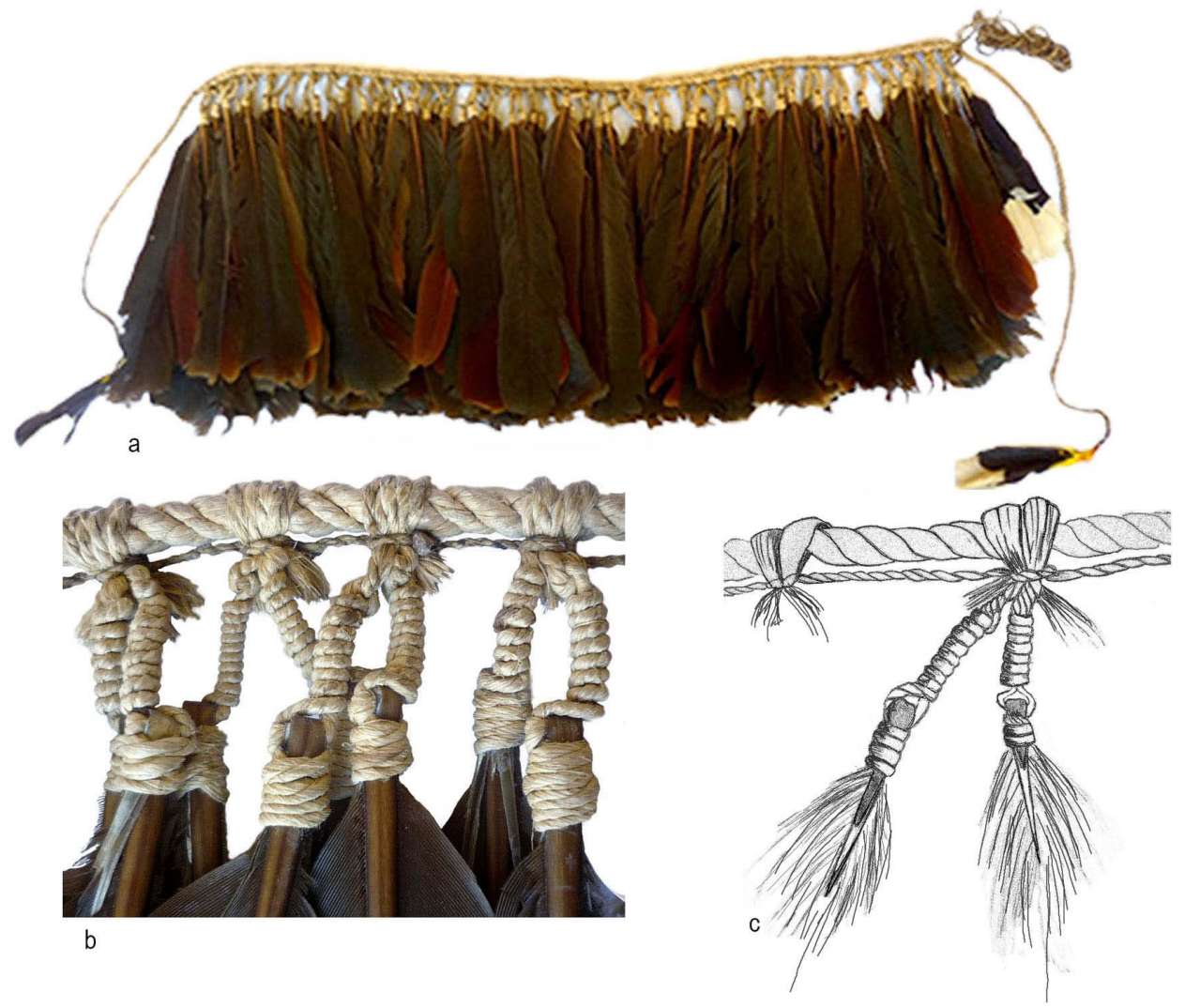

Figura 7. Cinturón ishir N 23461 (ME, FFyL, UBA), colección Ambrosetti a. Cinturón; b. Detalle de la sujeción de los haces de plumas; c. Técnica de sujeción de los haces de plumas (dibujo por Silvia Manuale). 
Figura 8. Cinturón ishir $\mathrm{N}^{\circ}$ 2346o (ME, FFyL, UBA), colección Ambrosetti a. Cinturón; b. Técnica de sujeción del haz de plumas (dibujo por Silvia Manuale).

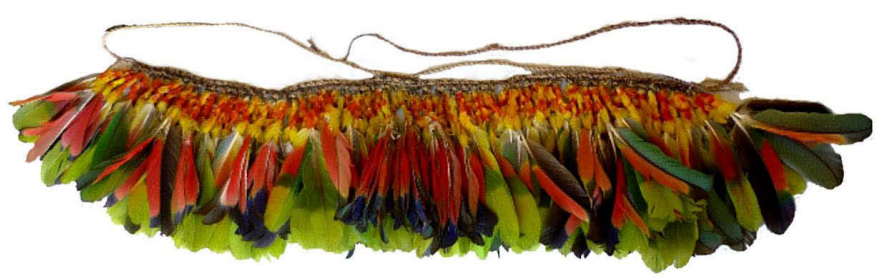

a

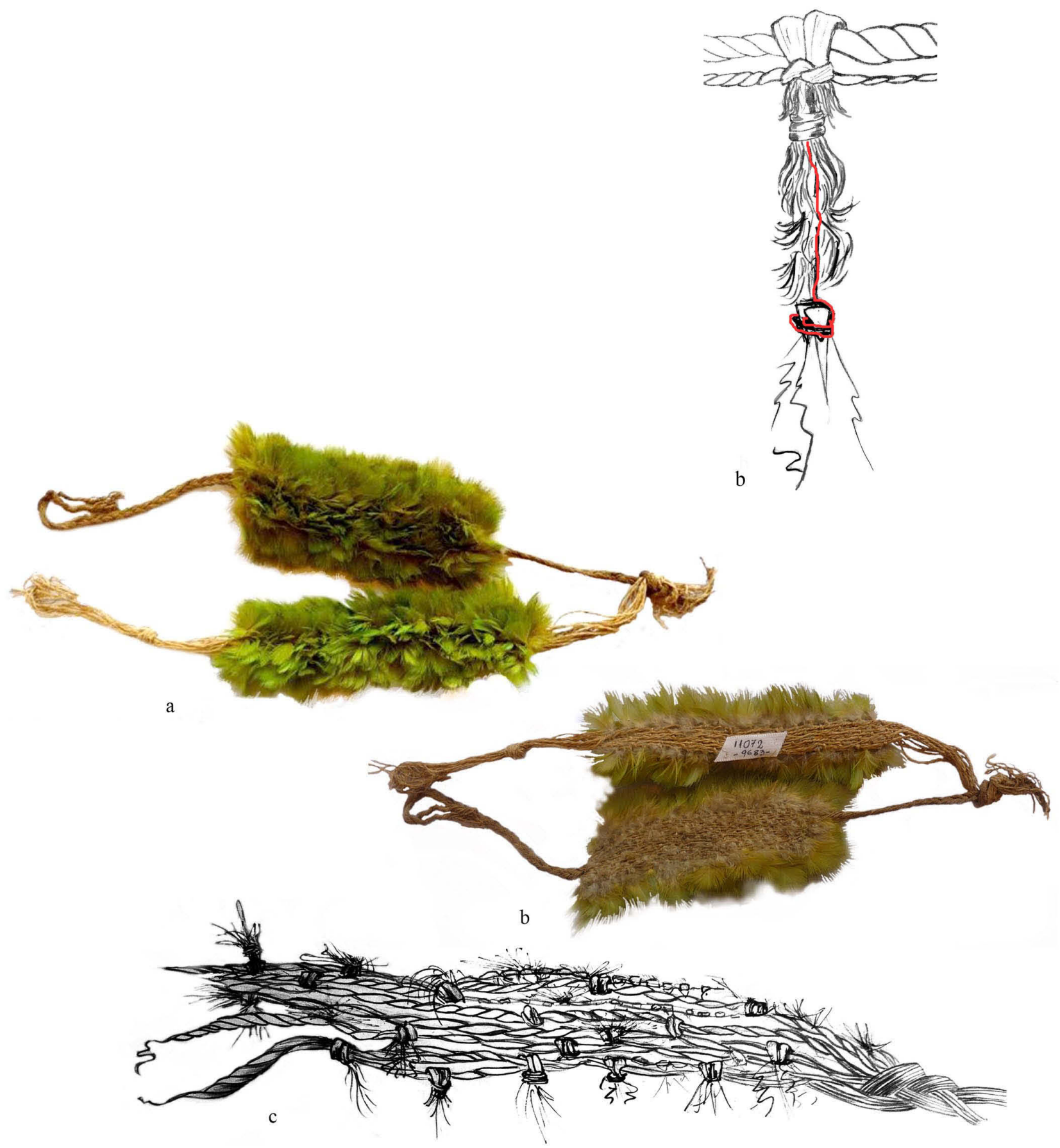

Figura 9. Adorno para miembros $\mathrm{N}^{\circ} 11072$ (ME, FFyL, UBA), colección Aguirre. a. Anverso; b. Reverso; c. Técnica de sujeción de plumas (dibujo por Silvia Manuale) 
Figura 10. Vincha chorote $\mathrm{N}^{\mathrm{o}} 5664$ (ME, FFyL, UBA), colección Debenedetti. a. Vincha; b. Detalle de la técnica faz de urdimbre; c. Dibujo de la técnica faz de urdimbre (Seiler Baldinger 1994: 89).
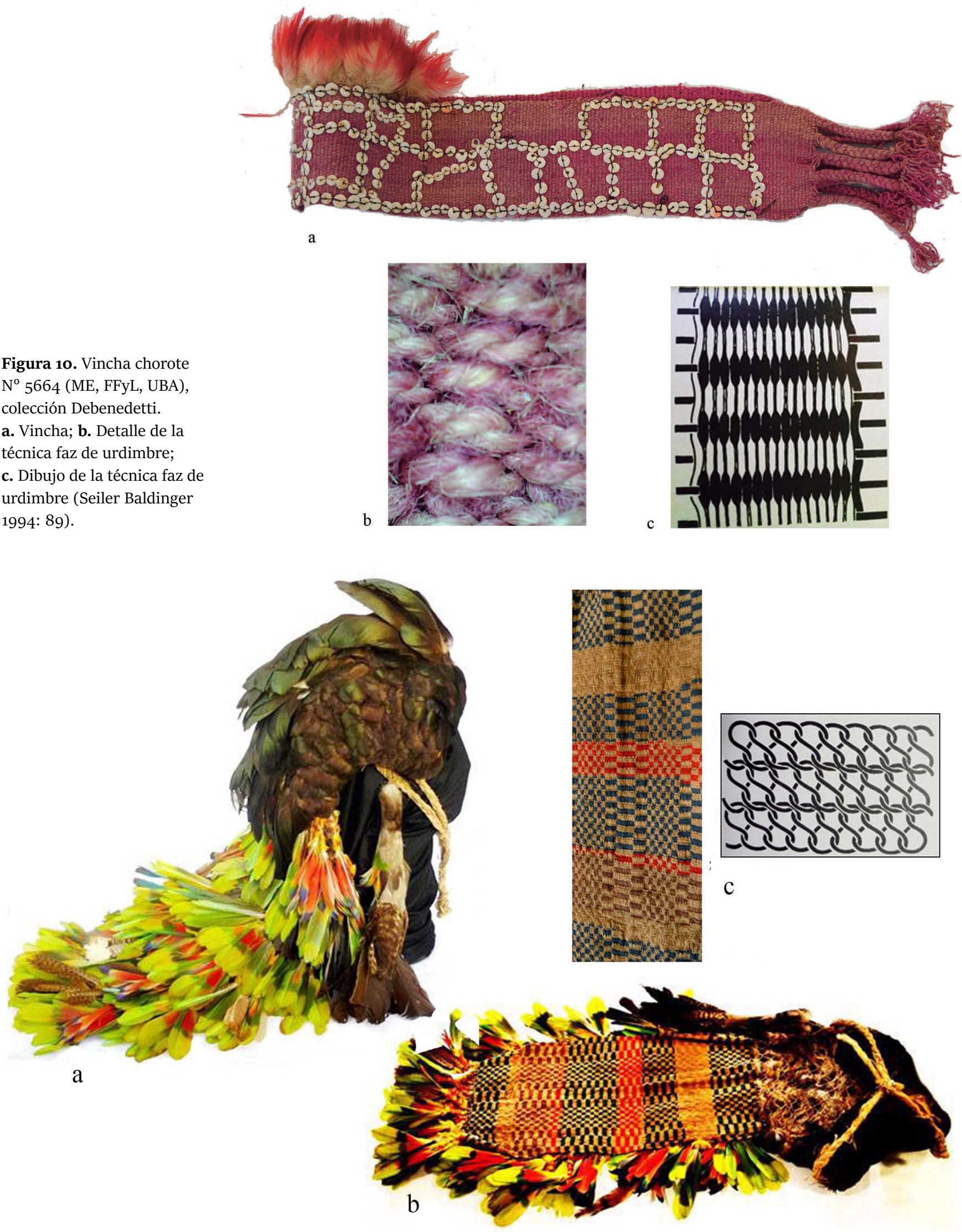

Figura 11. Tocado ishir 11074 (ME, FFyL, UBA) a. Anverso b. Reverso c. Dibujo de la técnica de malla (Seiler Baldinger 1994: 15). 

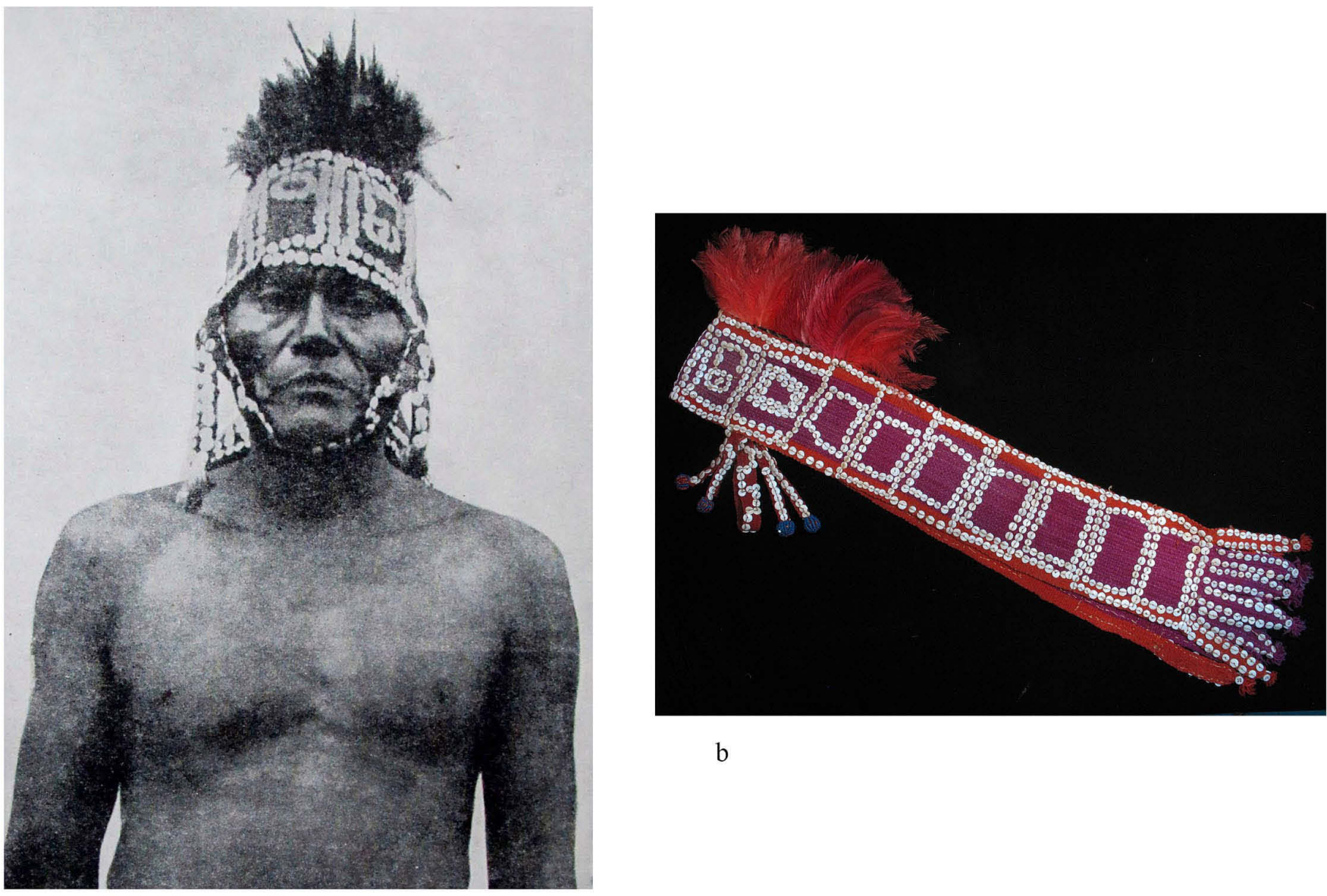

b

a

Figura 12. a. Shamán wichí, publicado por Palavecino (1936: 409) como "Hechicero mataco de Bazán (Formosa)”; b. Vincha wichí N 41800 (ME, FFyL, UBA).

objetos con plumas entre los wichí de Formosa (Palavecino 1936). Este último autor se refiere al usuario de una vincha roja con plumas y con apliques de conchas como "hechicero"; aquel objeto hoy se halla conservado en el Museo Ambrosetti (Figura 12). El empleo de los diferentes tipos de accesorios plumarios para la vestimenta, tales como los tocados, las tobilleras y muñequeras, ha sido investigado en territorio ishir; donde se han registrado los nombres en su lengua originaria y los significados del uso de cada accesorio y de los tipos de plumas y especies de aves (Escobar 1999, 2012). En el chaco argentino, las vinchas o tocados con plumas también habrían sido utilizados por los guerreros, es decir, en contextos de conflictos como los registrados entre los toba - pilagá y los nivaclé (Bossert y Siffredi 2011).

Actualmente, diferentes tipos de tocados con plumas son portados por los líderes pertenecientes a diversos pueblos originarios del Gran Chaco (Figura 13); este tipo de prenda hoy representa la autoridad política y la identidad indígena en contextos de diálogo con el estado o en manifestaciones diversas por las demandas relacionadas con la defensa del territorio.

\section{Metodología de investigación del patrimonio etnográfico con plumas}

El trabajo de documentación de las colecciones plumarias del Gran Chaco implicó varias etapas de investigación, algunas de las cuales aún están en pleno desarrollo. Se inició con el Proyecto de documentación de colecciones plumarias ishir del Museo etnográfico de la UBA (Di Lorenzo 2007), el cual abarcó la revisión bibliográfica sobre el pueblo ishir y los usos del acervo plumario; el estudio de las técnicas plumarias de manufactura de cada parte de la indumentaria y sus accesorios; la identificación de las especies de aves utilizadas en la confección de los mismos; la observación de patrimonio plumario ishir exhibido en los museos de San Lorenzo y Asunción en Paraguay con el objetivo de recabar datos sobre la materialidad y los significados atribuidos al uso de la plumaria (Figura 14); y finalmente, la realización de entrevistas a representantes ishir para el registro de información referente a los usos pasados y actuales de la cultura material plumaria (Di Lorenzo et al 2016). La consulta en el archivo institucional de Buenos Aires nos brindó 

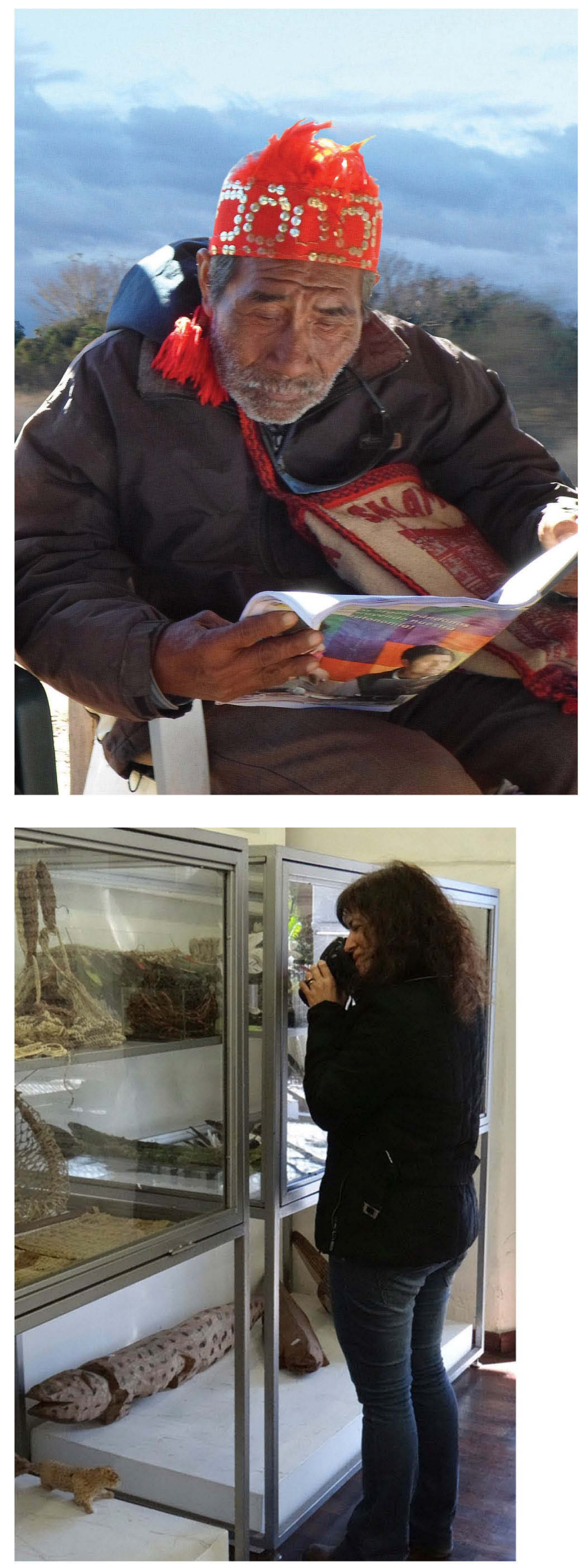

Figura 13. León Ramírez, nivaclé de Formosa (foto de Alicia Blanco) usando vincha de lana roja con apliques de lentejuelas metálicas doradas.

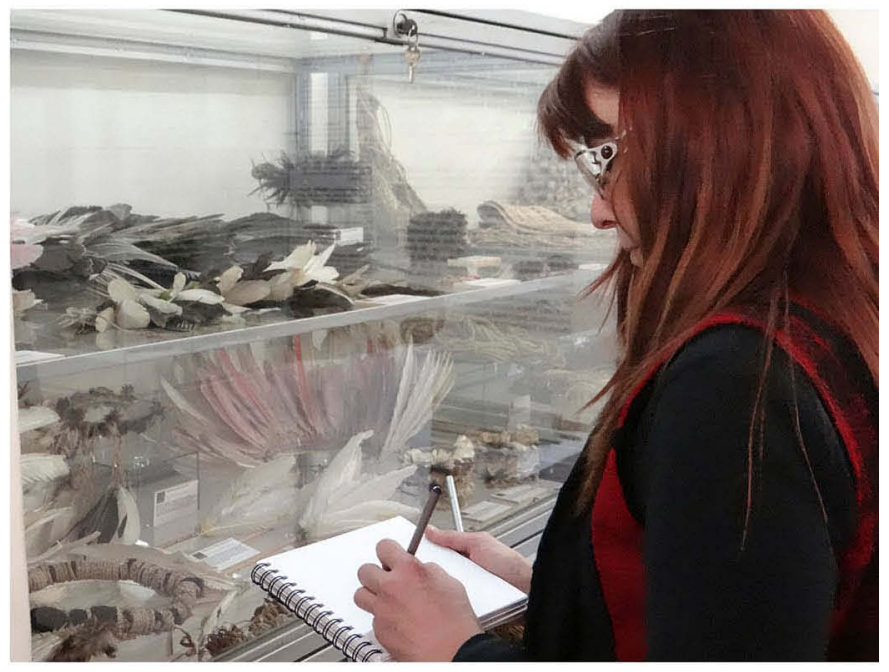

Figura 14. Registro de datos en el Museo Guido Boggiani, San Lorenzo, Paraguay. 
$a-b$
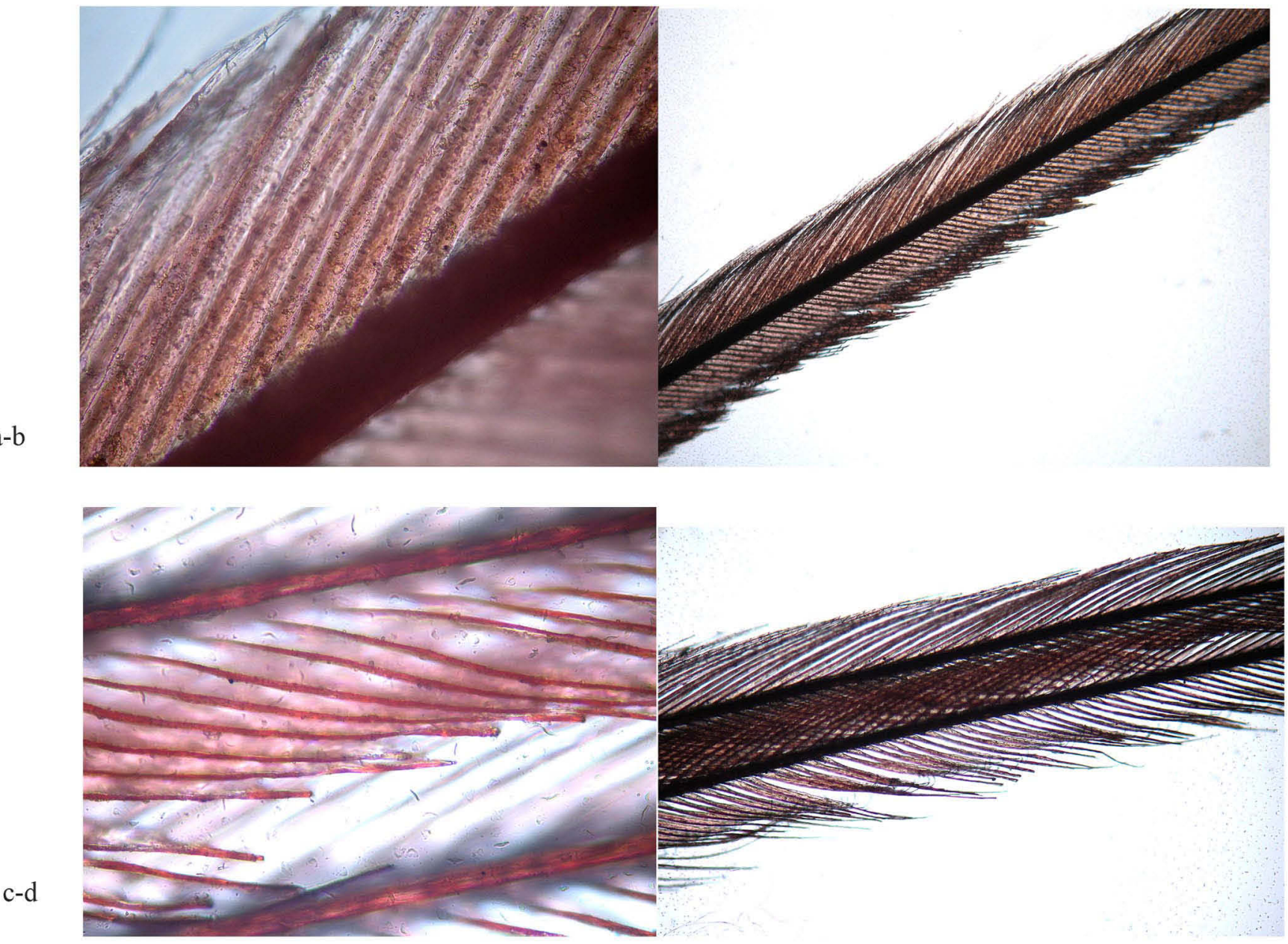

Figura 15. Plumas observadas con microscopio óptico: a y b. Pluma remera de loro hablador (40X y $5 \mathrm{X}$, respectivamente); c y d. Plumones observados con microscopio óptico (40X y 5X, respectivamente).

principalmente la posibilidad de analizar las fuentes procedentes del chaco argentino, a través del Fondo Documental Enrique Palavecino. Entre los relatos míticos del pueblo wichi recogidos por este etnógrafo en la década de 1930, es interesante señalar la alusión a las aves como parte de la cosmovisión originaria en territorio ancestral formoseño (Di Lorenzo 2016). El registro y análisis de las técnicas plumarias de los pueblos del chaco argentino junto a la lectura de las publicaciones de Palavecino, pertenecientes a los pilagá y wichi completan hasta ahora la información buscada para la documentación del patrimonio etnográfico plumario.

\section{Características del material plumario y algunas} consideraciones para su conservación:

La pluma (Figura 15) se considera como uno de los materiales más sensibles a las alteraciones físicas y químicas. De naturaleza orgánica, la pluma está constituida por un $91 \%$ de proteína, $8 \%$ de agua y $1 \%$ de lípidos (Bishop Museum
1996). El tipo de proteína es la queratina, pero de una clase diferente a la de la lana, ya que comparten diferente proporción de aminoácidos (Tímár-Balázsy 1998).

Una pluma típica, del estilo cobertera posee un cálamo en su parte inferior y un raquis que lo continúa, eje desde el cual nacen numerosas barbas y bárbulas; a este sector de las barbas se lo denomina vexilo o estandarte (Hickman et al 1986).

Existen diferentes tipos de plumas, las cuales tienen diferentes funciones en las aves (Figura 16). Es importante conocer esta clasificación ya que los tratamientos de conservación pueden variar según sea por ejemplo, una pluma cobertera o un plumón, siendo este último caracterizado por tener un aspecto enmarañado debido a la inexistencia de ganchos entre las barbas (Van Tyne y Berger 1966). En este sentido, en un trabajo publicado sobre limpieza de plumas se sugiere el uso de solventes polares para el tratamiento en plumones, mientras que en plumas con vexilo y 


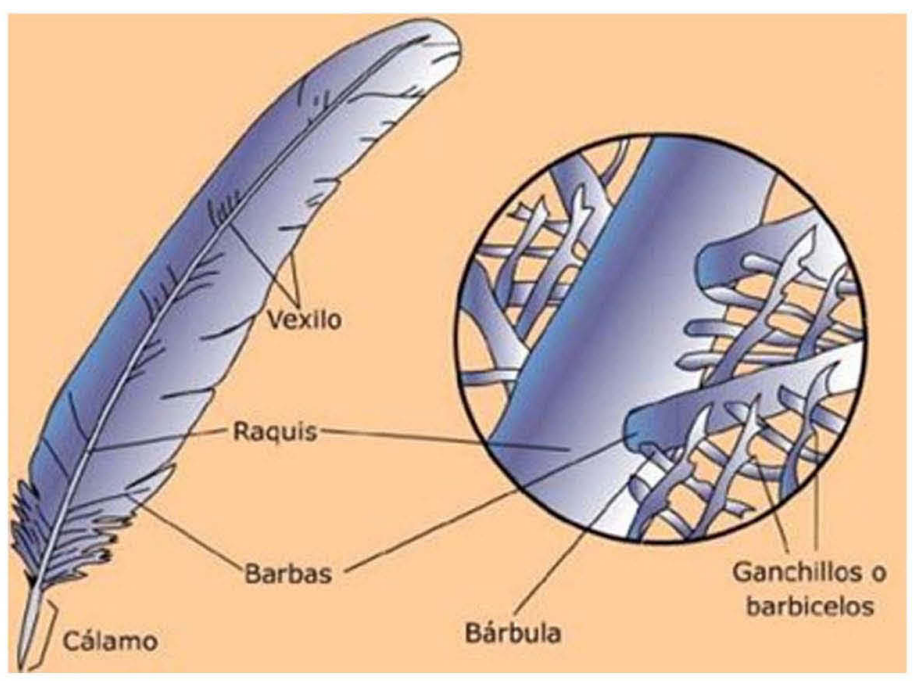

a

Figura 16. a. Partes de una pluma (http://entrepinosysembrados.blogspot.com/2014/11/tipos-de-plumas-en-las-aves.html, accedido el 10 de septiembre de 2019).

b. Tipos de plumas (modificado de https://askabiologist.asu.edu/explore/feather-biology, accedido el 10 de septiembre de 2019).

raquis sería más adecuado la aplicación de solventes no polares para minimizar posibles deterioros (Macías Flores y Blas Rojas 2012).

Es importante conocer también el origen de los colores de las plumas antes de la realización de tratamientos invasivos, con el objetivo de evitar nuevos deterioros, muchas veces no observables a simple vista. Así, los de origen pigmentario como los carotenoides, aquellos que dan los colores rojos, amarillos y naranjas, son lipocromos o de origen graso, por lo tanto deben evitarse las limpiezas con solventes orgánicos como el alcohol a riesgo de remover el pigmento (Pettingill 1958). Las melaninas, que otorgan los colores oscuros como los negros, marrones y grises, están conformadas por gránulos que podrían ser solubles en ácidos (Wallace 1959). Los colores de origen estructural como los azules se producen por la incidencia de la luz sobre la superficie de las barbas.

En otras palabras, no hay pigmentos azules; si observamos con luz transmitida de un microscopio podemos ver que las plumas azules son marrones y que las plumas verdes aparecen como amarillas; esto es consecuencia de la visibilidad de los pigmentos subyacentes (Wallace 1959 en Di Lorenzo 2018).

Los colores iridiscentes también son de origen estructural y se relaciona con el fenómeno óptico de reflexión de ondas de luz sobre las superficies opacas de las barbas (Pettingill
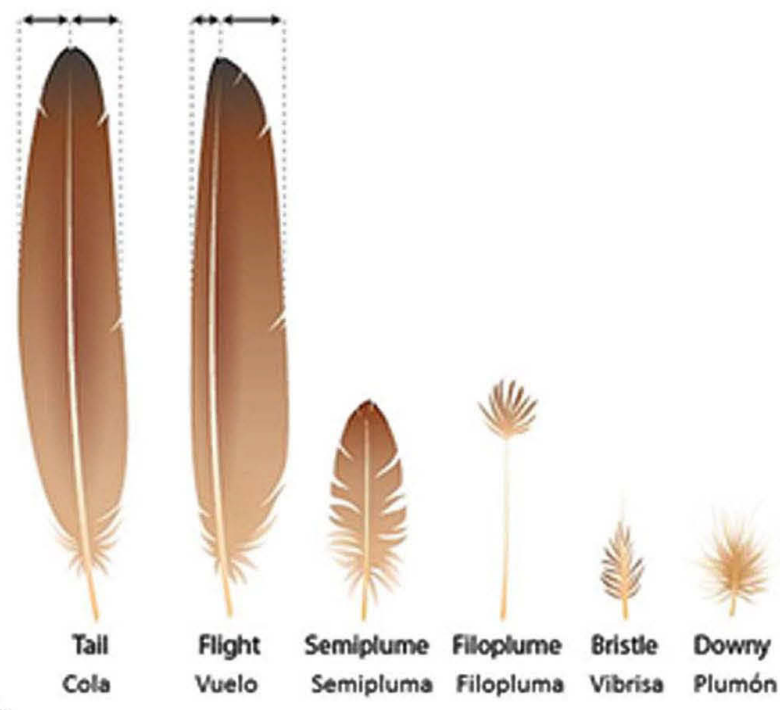

b

1958). Muchas veces, la limpieza de este tipo de plumas puede ocasionar el desorden de las barbas y bárbulas y consecuentemente retirar el brillo iridiscente de las mismas.

La actividad de acicalamiento de las aves, principalmente de las acuáticas, las cuales frotan sus picos contra la glándula uropígea haciendo que su aceite sea distribuido sobre las plumas para lubricar y limpiarlas (Wallace y Mahan 1975) es un dato importante que ha sido tenido en cuenta por algunos trabajos que han replicado de alguna forma este tipo de limpieza. El trabajo con geles en tratamientos húmedos (Amezaga Ramos 2006) y la aplicación de aceites cítricos esenciales para la recuperación de la iridiscencia de las plumas (Macías Flores y Blas Rojas 2012) constituyen ejemplos de intervención que han sido evaluados con resultados positivos por sus autores y que tomaron en cuenta la necesidad de no retirar en lo posible la grasa constitutiva de la pluma.

\section{Acciones de conservación preventiva para el cuidado de colecciones plumarias:}

La conservación de patrimonio plumario es considerada dentro de un plan de manejo integral de las colecciones, el cual comprende diferentes pasos para su preservación a largo plazo, disponible y accesible a las generaciones presentes y futuras. 
La documentación, como se mencionó en este trabajo, es fundamental para la obtención de datos que ayuden a elaborar adecuados diagnósticos del estado de conservación y realizar propuestas de tratamientos para prolongar la existencia de objetos con materialidades vulnerables.

Es importante la contemplación de requerimientos concretos de los tipos de objetos compuestos por materiales orgánicos, tales como la pluma y el textil para el almacenaje en la reserva técnica, el transporte y la exhibición.

La guarda de esta clase de patrimonio en contenedores realizados con material inerte evita su exposición innecesaria a las partículas de polvo; y la construcción de bandejas y soportes de guarda reduce su manipulación, a la vez que ofrece un apoyo ergonómico y suave, adaptable al espacio de la reserva técnica. El uso de envoltorios como el papel libre de ácido contribuye a una mayor protección, principalmente en sectores donde el ambiente no está controlado. El mobiliario apto para su guarda permanente debería ser metálico con pintura epóxica, por su alta resistencia química y por carecer de disolventes que podrían afectar las colecciones.

La exhibición en vitrinas de formato cerrado es una barrera contra el ingreso de contaminantes y plagas, a la vez que es una medida de seguridad frente al vandalismo. Los objetos, principalmente los tridimensionales, como por ejemplo los tocados ishir, deberían ser expuestos sobre soportes adecuados, de manera tal de amortiguar la acción de las fuerzas físicas y así evitar posibles deterioros provenientes de la abrasión, aplastamiento y posterior rotura de las barbas de las plumas. Por otro lado, el descanso de los objetos sobre soportes evitaría las tensiones originadas por la concentración de las fuerzas en uno o dos puntos.

El transporte de objetos patrimoniales es uno de los momentos en que aumenta el riesgo de deterioro y pérdidas que son irreversibles. Por este motivo, es importante evitar en la medida de lo posible el movimiento de los objetos durante el traslado y colocar material que amortigüe pequeños desplazamientos, para minimizar probables desprendimientos de las barbas plumarias. Existe una categoría de material de conservación temporario o semipermanente, que es amortiguador como la espuma de poliuretano de alta densidad, que no son inertes pero que puede colocarse en los contenedores de transporte, sin estar en contacto directo con los objetos. Una vez realizado el traslado, este material inestable debe ser retirado y los objetos, guardados con material de calidad permanente.

Así, los materiales de conservación utilizados para la reserva como para exhibición deben cumplir con las características de estabilidad química y física, propiedad que los hace relativamente durables en el tiempo.

El monitoreo sistemático de humedad relativa y temperatura también debe ser un requisito para la preservación de las colecciones; ya que es necesario conocer las condiciones ambientales existentes y los requisitos que presenta la materialidad implicada para así poder prever acciones que ayuden a mantener las colecciones en condiciones lo más adecuadamente posible. La pluma, al ser de naturaleza higroscópica, requiere de unas condiciones estables, es decir no fluctuantes de humedad relativa, en un rango que no sea inferior al $40 \%$, a riesgo de tornarla frágil y promover roturas, pero que no sobrepase el $65 \%$, por su disposición a ser afectada por microorganismos (Schaeuffelhut et al. 2002).

La manipulación del patrimonio siempre tiene que ser a través del empleo de guantes, preferiblemente de nitrilo o de látex sin polvo, para protección personal y para resguardo de las colecciones.

Dentro de una perspectiva de gestión de colecciones, la contemplación de directrices, procedimientos y normas ayudarán a la toma de decisiones para la adecuada preservación del patrimonio plumario etnográfico.

\section{Consideraciones finales}

El patrimonio plumario etnográfico, en ocasiones combinado con otras materialidades representa un material altamente sensible que para ser preservado necesita de una determinada metodología de conservación, estudio y análisis. La documentación es un paso fundamental para la preservación de las colecciones y en este camino, se plantea el uso del dibujo científico y de la fotografía, como herramientas adecuadas que contribuyen a la obtención de información, a la vez que mejoran o sirven para hacer un uso racional de objetos con materialidad sensible, al minimizar la manipulación. El trabajo con este tipo de colecciones implica una responsabilidad considerable, que debe contemplar los criterios de acción de la conservación preventiva, en las diferentes etapas de estadía del patrimonio, es decir, en las reservas, exposiciones y traslados. Así como también se torna necesaria la realización de estudios analíticos en las colecciones plumarias para la detección de posibles pesticidas colocados en el pasado, con el objetivo de establecer estrategias de acción para la manipulación de objetos contaminados y evaluar adecuados tratamientos.

Finalmente queremos señalar que es hora de aceptar el desafío de conservar productos materiales de las sociedades originarias actuales que hoy se custodian en los museos y permitir su uso frente a la demanda actual por parte de las comunidades representadas. Desafío que implica encontrar la manera de hacer accesible un patrimonio, muchas veces considerado sagrado fuera de la institución, realizando un uso seguro para los pueblos actuales y cuidadoso para el patrimonio, es decir, disponible para las generaciones futuras. 


\section{Referencias citadas}

Alvarado Pérez, Margarita y Miguel A. Azócar Magüida.

1994 Documentación y conservación: dos aspectos de la conservación preventiva. Boletín del Comité Nacional de Conservación Textil 2: 19-24.

Amezaga Ramos, Mercedes.

2006 Restauración de plumería sobre tejido en el Museo de América: aplicación de nuevas tecnologías. Anales del Museo de América 14: 381-406.

Berger, John

2017 Sobre el dibujo. Gráficas 92, Barcelona.

Bishop Museum.

1996 The care of feathers. The State Museum of Natural and Cultural History, Honolulu. http://www.bishopmuseum.org/research/pdfs/cnsv-feathers.pdf, accedido el 11 de septiembre de 2019.

Bossert, Federico y Alejandra Siffredi.

2011 Las relaciones interétnicas en el Pilcomayo medio: la guerra indígena y sus transformaciones (1882-1938). Población \& Sociedad 18 (1): 3-48. ISSN 0328-3445, accedido el 10 de septiembre de 2019.

Cordeu, Edgardo.

1980 Aishnuwérhta. Las ideas de deidad en la religiosidad chamacoco. Tesis doctoral. Facultad de Filosofía y Letras, Universidad de Buenos Aires. Copia cedida por el autor.

Di Lorenzo, Silvana

2007 Proyecto de documentación de colecciones plumarias ishir del Museo etnográfico de la UBA. Manuscrito en Área de Conservación y Museografía, Museo Etnográfico Juan B. Ambrosetti, Universidad de Buenos Aires.

2018 Conservación de material plumario en bienes culturales. Caso de estudio: el tocado de plumas ishir del Museo Etnográfico Juan Bautista Ambrosetti (FFyL), Universidad de Buenos Aires. Tesis de maestría inédita. Tarea-IIPC Investigaciones sobre el Patrimonio Cultural, Universidad Nacional de San Martín.

Di Lorenzo, Silvana, Silvia Manuale y Diego Olivera.

2016 El pueblo ishir y las plumas sagradas del Chaco paraguayo. Una mirada a las colecciones del Museo Etnográfico "Juan B. Ambrosetti” de la Universidad de Buenos Aires. Actas de la XXIX RAE 2015 La rebelión de los objetos. Arte plumario: 223-250, La Paz.

Escobar, Ticio

1999 La maldición de Nemur. Acerca del arte, el mito y el ritual de los indígenas Ishir del Gran Chaco Paraguayo. Centro de Artes Visuales / Museo del Barro, Asunción. 2012 La belleza de los otros. Arte indígena del Paraguay. Servilibro, Asunción.

Hickman, Cleveland; Larry Roberts y Frances Hickman. 1986 Zoología. Principios Integrales. EMALSA, S.A., Madrid.
Icon News

2015 A drawing is worth a thousand words. Julio 59: 11-13, accedido el 10 de septiembre de 2019.

Macías Flores, Samira y Claudia Blas Rojas.

2012 Restauración de objetos con plumas en las colecciones del acervo etnográfico del Museo Nacional de Antropología. IX Foro Académico de Ciencia, Creación y Restauración. Escuela de Restauración y Conservación de Occidente. Guadalajara, Jalisco, México, http://www.ecro.edu.mx/pdf/pdf memorias/samira macias.pdf, accedido el 11 de septiembre de 2019.

Palavecino, Enrique.

1936 Las Culturas aborígenes del Chaco. Historia de la Nación Argentina I: 387-418. Academia Nacional de la Historia de Buenos Aires.

Pegoraro, Andrea y Mariana A. Elías.

2010 Documentación de colecciones etnográficas: los desafíos de los tiempos actuales. El caso de las colecciones etnográficas del Museo Etnográfica “J. B. Ambrosetti” de la Universidad de Buenos Aires. $1^{\circ}$ Congreso Nacional de Museos Universitarios, Universidad de La Plata. http://sedici.unlp.edu.ar/bitstream/handle/10915/41723/Documento completo. pdf? sequence $=1$, accedido el 15 de septiembre de 2019.

Pettingill, Olin Sewall.

1958 A Laboratory and Field Manual of Ornithology. Burgess Publishing Company, Minnesota.

Roubillard Escudero, Marcela.

2008 Fotografía documental. En: Manual de registro y documentación de bienes culturales, editado por Lina Nágel Vega, pp. 30-40 Centro de Documentación de Bienes Patrimoniales, DIBAM, Santiago de Chile.

Schaeuffelhut, Stephanie; Helen Tello y Simone Schneider.

2002 Cleaning of feathers from the Ethnological Museum, Berlin. En The Conservation of Fur, Feather and Skin, editado por Margot M. Wright, pp. 63-68. CEA Series 3, Archetype Publications, London.

Seiler Baldinger, Anne Marie.

1994 Textiles. A Classification of Techniques. Smithsonian Institute Press, Washington DC.

Timár-Balázsy, Agnes y Dinah Eastop.

1998 Chemical Principles of Textile Conservation. Butterworth - Heinemann, London.

Van Tyne, Josselyn y Andrew Berger.

1976 Fundamentals of Ornithology. Science Editions, by John Wiley and Sons Inc., New York.

Wallace, George.

1959 An Introduction to Ornithology. The Macmillan Company, New York.

Wallace, George y Harold Mahan.

1975 An Introduction to Ornithology. Macmillan Hungry Minds, New York. 